\title{
ANALISIS PENENTUAN PDD BERKAS FOTON 6 DAN 10 MV FREE FLATTENING FILTER (FFF) PADA LAPANGAN KECIL MENGGUNAKAN TIGA DETEKTOR YANG BERBEDA
}

\author{
Okky Agassy Firmansyah dan Assef Firnando Firmansyah \\ Pusat Teknologi Keselamatan dan Metrologi Radiasi-BATAN \\ Jl. Lebak Bulus Raya-Pasar Jum'at Jakarta Selatan \\ Email: okky-agassy@batan.go.id
}

Diterima : 10-04-2019

Diterima dalam bentuk revisi: 02-09-2019

Disetujui: 21-11-2019

\begin{abstract}
ABSTRAK
ANALISIS PENENTUAN PDD BERKAS FOTON 6 DAN 10 MV FREE FLATTENING FILTER (FFF) PADA LAPANGAN KECIL MENGGUNAKAN TIGA DETEKTOR YANG BERBEDA. Analisis penentuan persentase dosis kedalaman untuk berkas foton 6 dan $10 \mathrm{MV}$ flattening filter free (FFF) pada lapangan kecil menggunakan variasi detektor. Makalah ini menguraikan penentuan persentase dosis kedalaman dari berkas foton 6 dan 10 MV FFF yang dipancarkan pesawat pemercepat linier medik Versa HD. Pengukuran dilakukan menggunakan 3 jenis detektor yaitu IBA Razor dioda, PTW PinPoint 3D dan IBA CC13 yang dihubungkan dengan elektrometer IBA Dose 1. Pengukuran dilakukan di dalam fantom air Blue Fantom IBA yang dilengkapi dengan perangkat lunak MyQA Accept pada jarak sumber radiasi ke permukaan $100 \mathrm{~cm}$ dengan variasi lapangan radiasi $1 \times 1 \mathrm{~cm}^{2}, 2 \times 2 \mathrm{~cm}^{2}, 3 \times 3 \mathrm{~cm}^{2}$ dan $4 \times 4 \mathrm{~cm}^{2}$. Berdasarkan data yang didapatkan deviasi pengukuran antara detektor IBA Razor terhadap detektor PinPoint 3D didapatkan rentang deviasi $1.8 \%-2.1 \%$. Berbeda dengan deviasi pengukuran antara detektor IBA CC13 terhadap dektektor PinPoint 3D yang mendapatkan rentang deviasi $0,15 \%-0,21 \%$. Maka dapat disimpulkan bahwa pengukuran menggunakan tiga tipe detektor ini menunjukkan adanya kesesuaian dengan deviasi terbesar lebih kecil dari 3,5\%. Detektor PinPoint 3D, Detektor IBA Razor, dan IBA CC13 dapat digunakan untuk melakukan pengukuran relatif pada lapangan kecil hingga $1 \times 1 \mathrm{~cm}^{2}$ pesawat pemercepat linier medik.
\end{abstract}

Kata kunci : PDD, Lapangan Radiasi Kecil, Radiasi Pengion, IBA Razor Dioda, IBA CC13, PTW PinPoint 3D.

\section{ABSTRACT}

ANALYSIS OF PERCENTAGE DEPTH DOSE DETERMINATION FOR 6 AND 10 MV FLATTENING FILTER FREE (FFF) PHOTONS BEAMS AT SMALL FIELDS USING THREE DIFFERENTS DETECTORS. Analysis of percentage depth dose determination for 6 and $10 \mathrm{MV}$ flattening filter free (FFF) photon beams at small fields using various types of detector. This paper describes the measurement of the percentage depth dose for 6 and $10 \mathrm{MV}$ flattening filter free (FFF) photon beams produced from an Elekta Versa HD linear accelerator machine. Measurement were carried out using three types of detector, IBA Razor dioda, PTW PinPoint 3D and IBA CC13. The measurement were performed inside inside the Blue Phantom IBA supported with MyQA Accept software for beam scanning at the source to surface distance of $100 \mathrm{~cm}$ with field sizes of $1 \times 1 \mathrm{~cm}^{2}, 2 \times 2 \mathrm{~cm}^{2}, 3 \times 3 \mathrm{~cm}^{2}$ and $4 \times 4 \mathrm{~cm}^{2}$. Based on the data obtained, the measurement deviation between the IBA Razor detector and the PinPoint 3D detector shows a deviation range of $1.8 \%-2.1 \%$. It is different from the measurement deviation between the IBA CC13 detector and the PinPoint $3 D$ detector which has a deviation range of $0.15 \%-0.21 \%$. So it can be concluded that the measurement using these three types of detectors shows that there is a match with the largest deviation smaller than 3.5\%. The PTW PinPoint 3D ion chamber, the IBA Razor Detector, and the IBA CC13 ion chamber can be used to make relative measurements to small fields up to $1 \times 1 \mathrm{~cm}^{2}$ of linear accelerators.

Keywords: PDD, Small Field, lonizing Radiation, IBA Razor Dioda, IBA CC13, PTW PinPoint 3D. 


\section{PENDAHULUAN}

Prevalensi kanker di Indonesia mencapai 4,3 per 1000 penduduk. Hal tersebut diketahui dengan statistic kasus kanker baru hampir 300 ribu per tahun. Di Indonesia kanker berada di peringkat ke enam sebagai penyebab kematian (1). Radioterapi merupakan salah satu pilihan pengobatan dalam mengatasi penyakit kanker selain operasi dan kemoterapi (2). Radioterapi bertujuan memberikan suatu dosis terukur ke suatu volume target tertentu untuk mematikan sel - sel tumor semaksimal mungkin tetapi dengan efek samping ke jaringan normal seminimal mungkin dengan harapan memperbaiki kualitas hidup dan memperpanjang kelangsungan hidup penderita $(3,4)$.

Di Indonesia beberapa tahun terakhir ini modalitas penatalaksanaan dalam radioterapi berkembang sangat pesat seperti intensity modulated radiation therapy (IMRT), volumetric arc therapy (VMAT) dan stereotactic radiosurgery (SRS) dengan penggunaan lapangan radiasi kecil yang berukuran $1 \times 1 \mathrm{~cm}^{2}$ atau lebih kecil (5). Salah satu kelebihan dari fitur penyinaran di lapangan radiasi kecil adalah penyinaran yang diberikan pada volume target tumor lebih akurat dan bersamaan dengan itu jaringan sehat di sekitarnya lebih terlindungi dari radiasi yang tidak diperlukan.

Dosimetri untuk lapangan radiasi kecil ini merupakan tantangan baru bagi peneliti ataupun fisikawan medis dibandingkan dengan dosimetri untuk lapangan radiasi standar baik untuk pengukuran absolut maupun relatif (6). Untuk pengukuran absolut ketertelusuran detektor pada lapangan kecil masih belum tersedia di laboratorium dosimetri standar primer mengingat adanya kesulitan teknis pada kalorimeter air yang digunakan untuk menentukan dosis serap air dan kalibrasi detektor ionisasi pada lapangan kecil. Untuk pengukuran relatif, dimensi, bahan, respon energi dan laju dosis detektor yang digunakan masih merupakan masalah tersendiri (7).

Ada beberapa karakteritik umum yang perlu dipenuhi oleh sebuah detektor untuk digunakan dalam pengukuran relatif: stabilitas, linieritas dosis, linieritas laju dosis, linieritas dosis per pulsa, resolusi spasial, ukuran detektor, orientasi, sinyal latar dan faktor lingkungan (7). Selain faktor tersebut, pengukuran oleh sebuah detektor juga dipengaruhi oleh efek gangguan (pertubation effect) yang disebabkan oleh material dan desain dari detektor (8). Hingga saat ini, belum terdapat detektor yang ideal untuk pengukuran relatif berkas foton/elektron pada lapangan kecil.

Teknologi penyinaran FFF masih tergolong baru di Indonesia. Jumlah pesawat pemercepat linier medik dengan fitur penyinaran berkas foton FFF baru terdapat di empat rumah sakit. Oleh karena itu diperlukan penelitian terkait karakteristik berkas radiasi pada pengukuran berkas foton FFF pada lapangan kecil dengan menggunakan dua atau tiga buah detektor dengan tipe yang berbeda.

Makalah ini menguraikan analisis penentuan persentase dosis kedalaman berkas foton 6 dan 10 MV FFF yang dipancarkan dari pesawat pemercepat linier medik Elekta Versa HD pada lapangan radiasi kecil menggunakan variasi detektor. 
Penelitian dilakukan di Rumah Sakit Mayapada Jakarta Selatan. Pesawat pemercepat linier medik Elekta Versa HD dan desain pengukuran dapat dilihat pada Gambar 1.

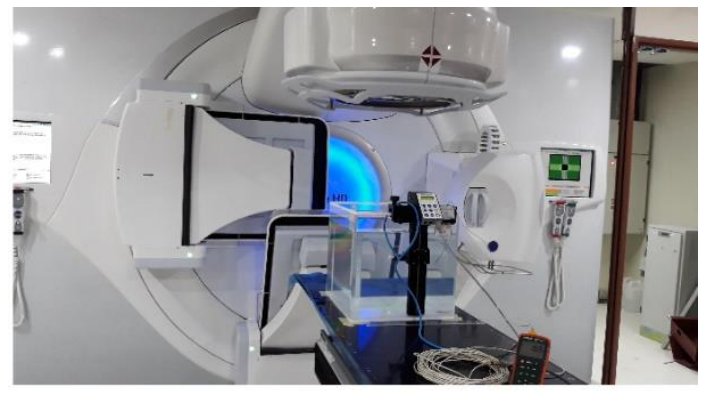

Gambar 1. Pesawat Pemercepat Linier Medik Elekta Versa HD

Tujuan dari penelitian ini adalah membandingkan pengukuran parameter dosimetri relatif prosentase dosis kedalaman (PDD) dengan menggunakan tiga buah detektor level terapi di lapangan radiasi kecil berkas foton $6 \mathrm{MV}$ dan $10 \mathrm{MV}$ FFF. Parameter yang telah diukur dapat digunakan sebagai data referensi untuk kebutuhan komisioning atau kebutuhan klinis rumah sakit.

\section{TATA KERJA}

Sumber radiasi yang digunakan adalah pesawat pemercepat linier medik Elekta Versa HD No. seri 154714 yang memancarkan berkas foton 6 dan $10 \mathrm{MV}$ menggunakan filter perata berkas radasi (flattening filter / FF) dan tanpa filter perata berkas radasi (flattening filter free / FFF). Pesawat ini juga memancarkan berkas elektron antara 4, 6, 8, 9, 10, 12, dan $18 \mathrm{MeV}$ (9). Lapangan radiasi maksimum pesawat pemercepat linier medik Elekta Versa HD adalah $40 \times 40 \mathrm{~cm}^{2}$. Laju dosis penyinaran dari pesawat ini mampu mencapai 1400 $\mathrm{MU} /$ min untuk berkas foton $6 \mathrm{MV}$ FFF dan 240 MU/min 10 MV FFF. Dosis penyinaran yang diberikan adalah $200 \mathrm{MU}$.

Detektor yang digunakan sebagai alat ukur radiasi adalah detektor IBA Razor diode (IBA Company), PTW PinPoint 3D (PTWGermany) dan IBA CC13 (IBA Company) yang dihubungkan dengan elektrometer IBA Dose I (IBA Company). Fantom air yang digunakan pada penelitian ini adalah Blue Phantom (IBA Company). Perangkat lunak yang dipakai untuk akuisisi data secara real time adalah MyQA Accept (IBA Company). Detektor Razor, PTW PinPoint 3D dan IBA CC13 dapat dilihat pada Gambar 2.

Detektor PinPoint 3D tipe 31016 dapat digunakan untuk pengukuran lapangan radiasi dari $2 \times 2 \mathrm{~cm}^{2}$ hingga $30 \times 30 \mathrm{~cm}^{2}$. Detektor PinPoint 3D tipe 31016 termasuk detektor dengan tipe ionisasi. Agostinelli dkk mengatakan detektor PTW 31014 PinPoint sebagai detektor pengukuran relatif mempunyai respon yang sangat baik terhadap penyinaran berkas foton berenergi tinggi (high energy photon) dari lapangan radiasi $2 \times 2 \mathrm{~cm}^{2}$ lapangan radasi $10 \times 10 \mathrm{~cm}^{2}$ (10).

Detektor Razor mampu melakukan pengukuran relatif dengan rentang lapangan radiasi $0,6 \times 0,6 \mathrm{~cm}^{2}$ hingga $5 \times 5 \mathrm{~cm}^{2}$. Detektor Razor merupakan detektor tipe semi konduktor. Pengukuran radiasi pada semua ukuran lapangan radiasi menunjukkan hasil yang baik (11). Berbeda dengan detektor Razor, detektor IBA CC13 memiliki dimensi volume aktif sebesar $0,13 \mathrm{~cm}^{2}$ sensitivitas $3.8 \times 10^{-9} \mathrm{C} / \mathrm{Gy}$. Detektor IBA merupakan jenis detektor kamar ionisasi. Muhammad 
dkk menunjukkan bahwa detektor IBA CC13 mampu melakukan pengukuran dengan variasi lapangan radiasi $1 \times 1 \mathrm{~cm}^{2}$ hingga 15 $x 15 \mathrm{~cm}^{2}$ (12). Tabel 1 merupakan spesifikasi ketiga detektor yang dipakai dalam pengukuran PDD.

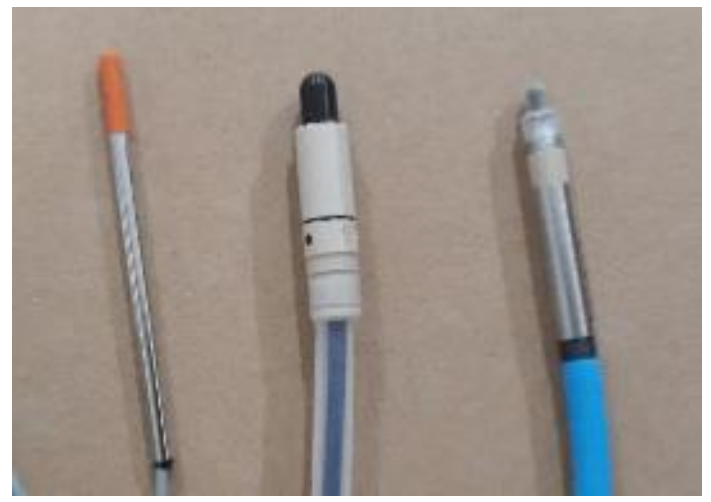

Gambar 2. Detektor IBA Razor, IBA CC13 dan PTW PinPoint 3D

Tabel 1. Spesfikasi Detektor yang digunakan

\begin{tabular}{llll}
\hline Detektor & IBA CC13 & PTW PinPoint 3D & IBA Razor Dioda \\
\hline Volume aktif & $0,13 \mathrm{~cm}^{3}$ & $0,016 \mathrm{~cm}^{3}$ & $0,017 \times 10^{-3} \mathrm{~cm} 3$ \\
Dimensi sensitive & Jari-jari : $3 \mathrm{~mm}$ & Jari-jari $: 1,45 \mathrm{~mm}$ & Jari-jari $: 0,3 \mathrm{~mm}$ \\
& Panjang $: 5.8 \mathrm{~mm}$ & Panjang $: 2.9 \mathrm{~mm}$ & Ketebalan : $20 \mu \mathrm{m}$ \\
Tahan Air & Ya & Ya & Ya \\
Respon & $1 \mathrm{nC} / \mathrm{Gy}$ & $400 \mathrm{pC} / \mathrm{Gy}$ & $4,1 \mathrm{nC} / \mathrm{Gy}$ \\
\hline
\end{tabular}

\section{Pengukuran Dosis Relatif}

Persentase dosis di kedalaman air disebut dengan PDD (Percentage Depth Dose). PDD merupakan kurva yang sangat penting karena merupakan salah satu parameter yang digunakan untuk penentuan laju dosis serap air. Demikian pula halnya dengan kedalaman acuan yang digunakan untuk menentukan posisi detektor di dalam air setiap energi nominal dari berkas elektron tersebut, hal ini sering disebut juga dengan istilah $Z_{\text {Ref. }}$

Pengukuran PDD didefinisikan sebagai hasil bagi persentase pengukuran dosis serap air pada sebuah kedalaman (Q) dengan kedalaman referensi $(P)$ yang tetap pada sebuah sumbu pusat (A).

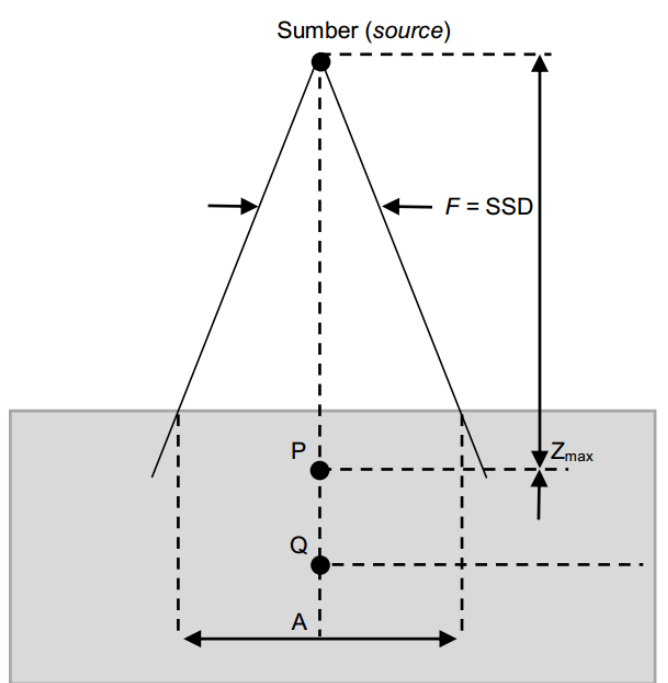

Gambar 3. Set Up Pengukuran PDD (13)

Dalam melakukan pengukuran dosis relatif, beberapa hal perlu dipertimbangkan antara lain: i) Detektor harus ditempatkan secara tepat di pusat berkas radiasi. ii) Karena lapangan radiasi kecil tidak memiliki dosis plateau di pusat berkas radiasi, maka penempatan detektor harus diperiksa dengan cara mengukur profil di kedalaman 
yang pendek dan dalam. iii) Efek volume dari detektor harus dihilangkan. Untuk menghilangkan efek volume dari detektor, maka diperlukan detektor dengan volume yang kecil untuk menghindari underestimate nilai dosis. iv) Waktu penyinaran yang panjang. Detektor harus ditempatkan sedemikian rupa detil, karena detektor volume kecil sering menunjukkan tingkat noise kuantum yang lebih tinggi dari pada detektor ionisasi yang digunakan dalam lapangan radiasi yang lebih besar (14).

Analisis PDD yang dilakukan adalah pada kedalaman $10 \mathrm{~cm}$ dan $20 \mathrm{~cm}$. Hasil pengukuran didapatkan dari perangkat lunak MyQA Accept buatan pabrikan IBA Dosimetry, Jerman. Perangkat lunak MyQA Accept memiliki fitur scanning berkas radiasi (advanced beam scanning) serta penyediaan data pengukuran dalam bentuk data $D_{10}, D_{20}$, $D_{s}$ (permukaan), $R_{100}\left(D_{\max }\right)$ beserta grafik.

\section{HASIL DAN PEMBAHASAN}

Hasil pengukuran persentase dosis kedalaman berkas foton 6 dan $10 \mathrm{MV}$ flattening filter free dari pesawat Versa HD pada lapangan radiasi $2 \times 2 \mathrm{~cm}^{2}$ dan $3 \times 3$ $\mathrm{cm}^{2}$ menggunakan detektor PinPoint 3D dan Razor dapat dilihat pada Tabel 2, sedangkan pada lapangan $4 \times 4 \mathrm{~cm}^{2}$ dengan detektor PinPoint 3D, Razor dan IBA CC 13 disajikan pada Tabel 3. Hasil juga disajikan dalam bentuk grafik PDD hasil pengukuran pada Gambar 4 dan Gambar 5.

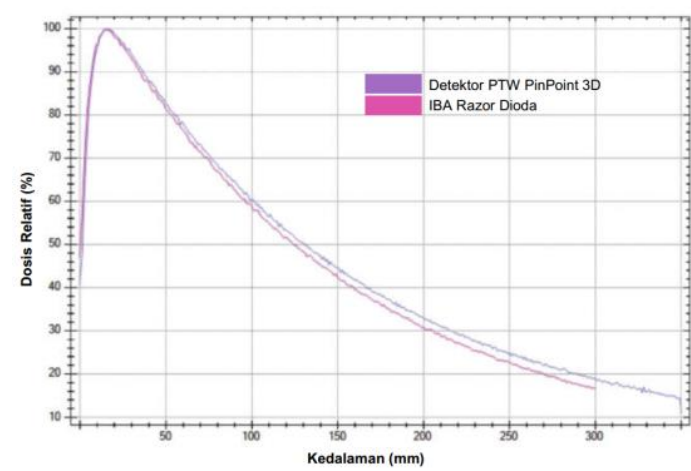

(a)

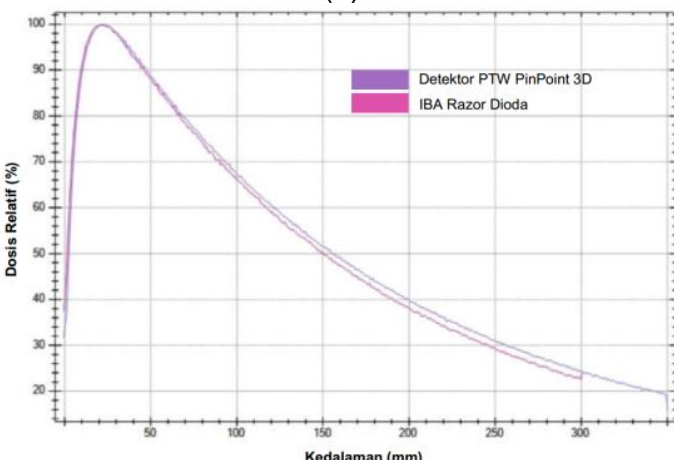

(b)

Gambar 4. Persentase dosis di kedalaman (a) berkas foton $6 \mathrm{MV}$ FFF (b) berkas foton $10 \mathrm{MV}$ FFF pada lapangan radiasi $2 \times 2 \mathrm{~cm}^{2}$ menggunakan detektor PinPoint 3D dan IBA Razor

Gambar 4.a merupakan grafik perbandingan pengukuran PDD menggunakan detektor PinPoint 3D dan detektor IBA Razor pada lapangan $2 \times 2 \mathrm{~cm}^{2}$ berkas foton 6 MV FFF. Berdasarkan kurva didapatkan nilai $D_{10}$ untuk detektor PinPoint 3D adalah 60,35\%, sedangkan detektor IBA Razor adalah 58,83\%. Terdapat selisih nilai sebesar 1,52\% lebih tinggi detektor PinPoint 3D. Hal tersebut juga terjadi pada pengukuran PDD berkas foton $10 \mathrm{MV}$ FFF (Gambar 4.b). Nilai $D_{10}$ untuk detektor PinPoint 3D adalah 67,39\%, sedangkan detektor IBA Razor adalah 58,83\%. Terdapat selisih nilai sebesar $1,26 \%$. 
Tabel 2. Parameter dosimetri relatif berkas foton 6 MV FFF dan 10 MV FFF yang diukur menggunakan detektor Razor, PinPoint 3D pada lapangan $2 \times 2 \mathrm{~cm}^{2}$ dan $3 \times 3 \mathrm{~cm}^{2}$

\begin{tabular}{clllll}
\hline \multirow{2}{*}{$\begin{array}{c}\text { Lapangan } \\
\text { Radiasi }\end{array}$} & \multirow{2}{*}{ Parameter } & \multicolumn{3}{c}{ 6 MV FFF } & 10 MV FFF \\
\cline { 2 - 5 } & & Razor & PinPoint 3D & Razor & PinPoint 3D \\
\hline \multirow{3}{*}{$2 \times 2 \mathrm{~cm}^{2}$} & $\mathrm{D}_{10}$ & $58,83 \%$ & $60,35 \%$ & $66,13 \%$ & $67,39 \%$ \\
& $\mathrm{D}_{20}$ & $30,81 \%$ & $33,12 \%$ & $38,11 \%$ & $39,76 \%$ \\
& $\mathrm{D}_{\mathrm{S}}$ & $49,49 \%$ & $42,61 \%$ & $39,74 \%$ & $33,22 \%$ \\
& $\mathrm{R}_{100}$ & $14,3 \mathrm{~mm}$ & $16,3 \mathrm{~mm}$ & $22,4 \mathrm{~mm}$ & $23,3 \mathrm{~mm}$ \\
$3 \times 3 \mathrm{~cm}^{2}$ & $\mathrm{D}_{10}$ & $60,67 \%$ & $61,81 \%$ & $67,69 \%$ & $69,15 \%$ \\
& $\mathrm{D}_{20}$ & $31,90 \%$ & $34,04 \%$ & $39,44 \%$ & $41,01 \%$ \\
& $\mathrm{D}_{\mathrm{S}}$ & $49,93 \%$ & $42,72 \%$ & $39,39 \%$ & $32,46 \%$ \\
& $\mathrm{R}_{100}$ & $17,4 \mathrm{~mm}$ & $17,3 \mathrm{~mm}$ & $22,4 \mathrm{~mm}$ & $22,3 \mathrm{~mm}$ \\
\hline
\end{tabular}

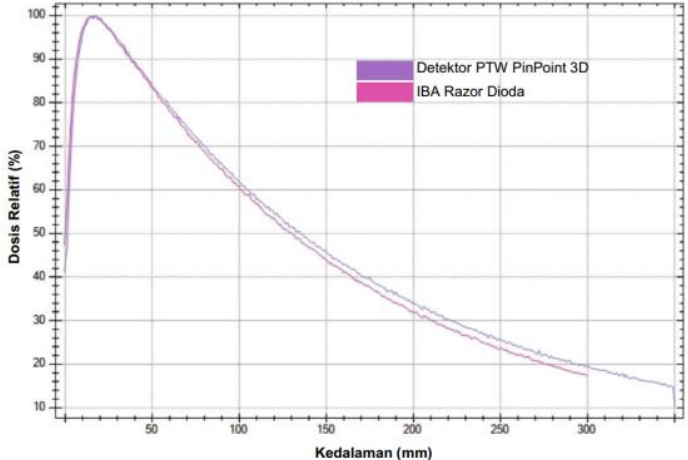

(a)

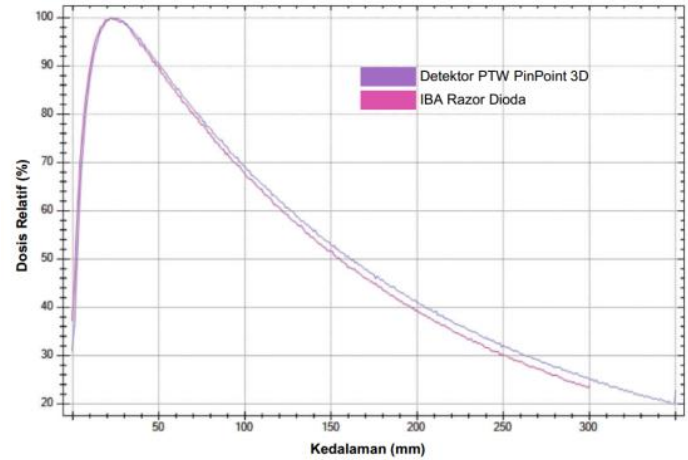

(b)

Gambar 5. Persentase dosis di kedalaman berkas foton 6 dan 10 MV FFF pada lapangan radiasi $3 x$ $3 \mathrm{~cm}^{2}$ menggunakan detektor PinPoint 3D dan IBA Razor.

Pola yang sama juga ditunjukkan oleh kedua detektor ini pada pengukuran PDD pada lapangan $3 \times 3 \mathrm{~cm}^{2}$. Gambar $5 . \mathrm{a}$ merupakan grafik perbandingan pengukuran
PDD berkas foton 6 MV FFF menggunakan detektor PinPoint 3D dan detektor IBA Razor. Dari kurva didapatkan nilai $\mathrm{D}_{10}$ untuk detektor PinPoint 3D adalah 61,81\%, sedangkan detektor IBA Razor 60,67\%, terdapat selisih nilai sebesar $1,14 \%$ lebih tinggi detektor PinPoint 3D. Hal tersebut juga terjadi pada pengukuran PDD berkas foton 10 MV FFF (gambar 5.b). Nilai $D_{10}$ untuk detektor PinPoint 3D adalah 69,15\%, sedangkan detektor IBA Razor 67,69\%. Terdapat selisih nilai sebesar $1,46 \%$.

Berdasarkan Tabel 2, pengukuran dengan menggunakan detektor PinPoint 3D dan detektor IBA Razor mendapatkan ratarata selisih pengukuran kurang dari $2 \%$. Perbedaan energi radiasi dari $6 \mathrm{MV}$ FFF menjadi 10 MV FFF memberikan pengaruh peningkatan pembacaan detektor berkisar antara $12 \%$. Peningkatan lapangan radiasi juga memberikan efek semakin besar nilai yang akan diukur oleh detektor. 
Analisis Penentuan PDD Berkas Foton 6 dan 10 MV Free Flattening Filter

(FFF) pada Lapangan Kecil Menggunakan Tiga Detektor yang Berbeda

Tabel 3. Parameter dosimetri relatif berkas foton 6 MV FFF dan 10 MV FFF yang diukur menggunakan detektor Razor, PinPoint 3D dan IBA CC 13 pada lapangan $4 \times 4 \mathrm{~cm}^{2}$

\begin{tabular}{lllllll}
\hline \multirow{2}{*}{ Parameter } & \multicolumn{3}{c}{ 6 MV FFF } & \multicolumn{3}{c}{ 10 MV FFF } \\
\cline { 2 - 7 } & Razor & CC 13 & PinPoint 3D & Razor & CC 13 & PinPoint 3D \\
\hline$D_{10}$ & $62,01 \%$ & $63,21 \%$ & $63,36 \%$ & $68,70 \%$ & $70,17 \%$ & $69,96 \%$ \\
$D_{20}$ & $33,33 \%$ & $34,72 \%$ & $34,99 \%$ & $39,84 \%$ & $41,69 \%$ & $42,17 \%$ \\
$D_{S}$ & $50,77 \%$ & $43,25 \%$ & $45,60 \%$ & $40,13 \%$ & $35,48 \%$ & $33,27 \%$ \\
$R_{100}$ & $14,3 \mathrm{~mm}$ & $17,6 \mathrm{~mm}$ & $15,3 \mathrm{~mm}$ & $25,4 \mathrm{~mm}$ & $25,8 \mathrm{~mm}$ & $25,4 \mathrm{~mm}$ \\
\hline
\end{tabular}

Hasil untuk pengukuran PDD lapangan $4 \times 4 \mathrm{~cm}^{2}$ dengan menggunakan tiga buah detektor disajikan pada Tabel 3, sedangkan grafik disajikan pada Gambar 6.a (untuk berkas foton $6 \mathrm{MV}$ FFF) dan 6.b (untuk berkas foton 10 MV FFF). Berdasarkan kurva didapatkan nilai $\mathrm{D}_{10}$ untuk detektor PinPoint 3D adalah $63,36 \%$, sedangkan detektor IBA CC13 mendapatkan nilai $63,21 \%$, dan detektor IBA Razor mendapatkan nilai $D_{10}$ sebesar $62,01 \%$.

Berdasarkan Tabel 3 didapatkan perbedaan nilai $\mathrm{PDD}_{10}$ diantara ketiga detektor paling besar 1,20\% pada berkas foton 6 MV FFF. Nilai tersebut merupakan selisih pengukuran antara detektor $\mathrm{CC} 13$ dengan IBA Razor, sedangkan untuk selisih pengukuran antara detektor IBA CC13 and PinPoint 3D mendapatkan selisih pengukuran $0.15 \%$. Pada pengukuran berkas foton 10 MV FFF didapatkan perbedaan paling besar $1,47 \%$ pada pengukuran antara detektor IBA razor dan IBA CC13, sedangkan untuk selisih pengukuran antara detektor IBA $\mathrm{CC} 13$ and PinPoint 3D mendapatkan selisih pengukuran $0.21 \%$. Perbedaan tersebut masih dibawah batas $2 \%$. Hasil tersebut menunjukkan adanya kesesuaian pengukuran yang cukup baik antara ketiga detektor tersebut.
Berkas foton 6 MV FFF mendapatkan nilai $D_{10}$ rata-rata $>60 \%$. Detektor PinPoint 3D mendapatkan nilai yang paling besar, yaitu $63,36 \%$, sedangkan pada berkas foton 10 MV FFF didapatkan nilai terbesar oleh detektor IBA CC13 dengan nilai 70,17\%.

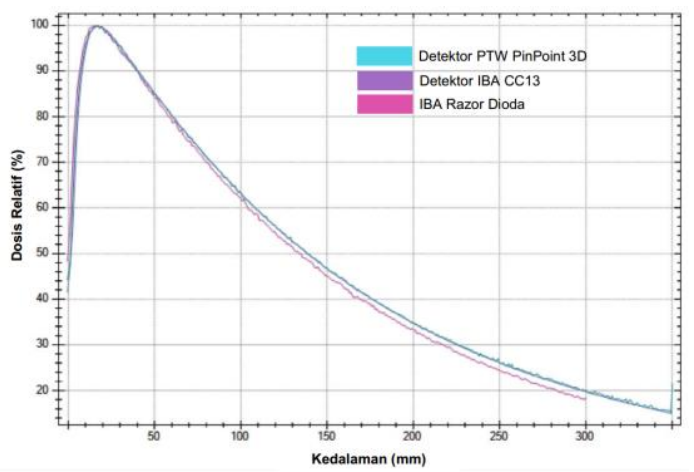

(a)

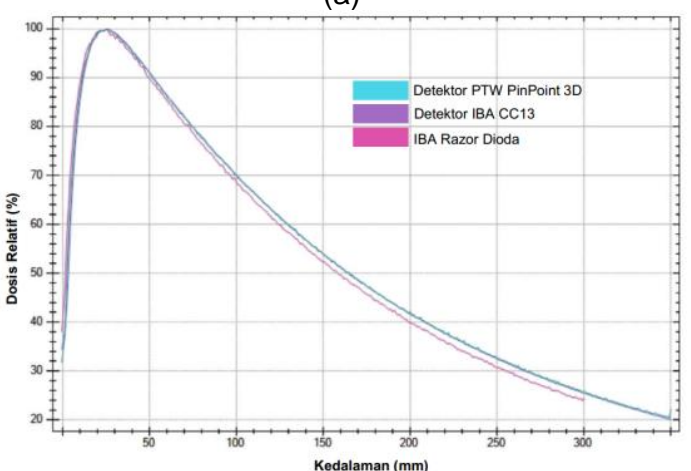

(b)

Gambar 6. Persentase dosis di kedalaman (a) berkas foton $6 \mathrm{~d}$ MV dan (b) berkas foton $10 \mathrm{MV}$ FFF pada lapangan1 radiasi $4 \times 4 \quad \mathrm{~cm}^{2}$ menggunakan detektor PinPoint 3D, detektor CC13 dan IBA Razor Dioda

Hasil data PDD dalam angka Berdasarkan Gambar 6 dapat dilihat juga bahwa kedalaman yang lebih jauh hasil pengukuran menggunakan detektor PinPoint 3D dan IBA CC13 mendapatkan hasil yang 
saling mendekati, namun untuk detektor IBA Razor mendapatkan hasil yang lebih rendah terhadap kedua detektor yang lain. Perbedaan tersebut dikarenakan spesfikasi dari detektor Razor memiliki ketergantungan tinggi pada laju dosis yang rendah. Selain itu, perbedaan juga disebabkan karena perbedaan material dan cara kerja dari ketiga detektor tersebut. Detektor PinPoint 3D dan IBA C133 merupakan detektor kamar ionisasi gas sedangkan detektor Razor merupakan detektor ionisasi yang bekerja dengan prinsip semikonduktor

Berdasarkan data yang didapat, deviasi pengukuran antara detektor IBA Razor terhadap detektor PinPoint 3D didapatkan rentang deviasi $1.8 \%$ - $2.1 \%$. Berbeda dengan deviasi pengukuran antara detektor IBA CC13 terhadap dektektor PinPoint 3D yang mendapatkan rentang deviasi $0,15 \%$ $0,21 \%$. Hal tersebut menunjukkan perbedaan bacaan yang diukur oleh detektor IBA Razor yang merupakan detektor dengan material penyusun diode dengan detektor IBA CC13 atau PinPoint 3D yang merupakan detektor ionisasi. Deviasi antara pengkuran detektor IBA CC13 atau PinPoint 3D yang didapatkan menunjukkan hasil kurang dari 1\%. Hal tersebut membuktikan pengukuran dengan menggunakan detektor IBA $\mathrm{CC} 13$ atau PinPoint 3D tidak menunjukkan perbedaan yang signifikan.

Detektor semikonduktor dioda cocok untuk pengukuran profil dari berkas foton pada lapangan kecil (15). Namun seperti yang telah disampaikan diatas, detektor ini mempunyai ketergantungan tinggi terhadap laju dosis yang rendah, sehingga mengurangi kemampuan pengukurannya. Hilangnya inherent shielding pada detektor razor mengakibatkan adanya pengukuran yang berlebih (overestimate measurement) pada dosis energi rendah, hal itu disebabkan oleh adanya peningkatan koefisien absorbsi relatif energi-massa untuk bahan silikon (11). Efek peningkatan ukuran lapangan radiasi juga memberikan pengaruh peningkatan dosis yang terukur karena adanya efek hamburan radiasi yang ikut terukur oleh detektor.

Detektor PTW PinPoint merupakan detektor tipe kamar ionisasi-mikro yang cocok untuk pengukuran dosis pada lapangan kecil (10). Kelebihan detektor ini dibandingkan dengan detektor resolusi tinggi (diamonds, diode, film) adalah kemampuan detektor dalam penentuan dosis dengan batasan energi dan parameter ketergantungan dosis, serta tidak memerlukan kalibrasi silang (cross calibration) pada saat pengukuran absolut, hanya butuh untuk menggunakan faktor koreksi.

Masih banyak kekurangan dalam pengukuran parameter dosimetri menggunakan detektor kamar ionisasi mikro, karena dibutuhkan resolusi bacaan yang tinggi, dan tidak terjadi kesetimbangan muatan partikel (lack of charge particle equilibrium). Meskipun telah terdapat rekomendasi detektor yang dapat digunakan untuk melakukanpengukuran dosimetri pada lapangan kecil, namun tidak ada satupun yang memenuhi persyaratan (12). Masih harus dikalkulasi dengan menggunakan faktor koreksi dan beberapa limitasi agar sesuai prosedur pengukuran. 


\section{KESIMPULAN}

PDD merupakan salah satu parameter dosimetri pada pesawat pemercepat linier medik yang harus dipastikan keakurasian datanya, karena data tersebut akan dimasukkan kedalam sistem perencanaan penatalaksanaan pasien (treatment planning system). Berdasarkan data yang didapatkan deviasi pengukuran antara detektor IBA Razor terhadap detektor PinPoint 3D didapatkan rentang deviasi $1.8 \%-2.1 \%$. Berbeda dengan deviasi pengukuran antara detektor IBA CC13 terhadap dektektor PinPoint 3D yang mendapatkan rentang deviasi $0,15 \%$ - 0,21\%. Maka dapat disimpulkan bahwa pengukuran menggunakan tiga tipe detektor ini menunjukkan adanya kesesuaian dengan deviasi terbesar lebih kecil dari 3,5\%. Ketiga detektor yaitu detektor PinPoint 3D, Detektor IBA Razor, dan IBA CC13 dapat digunakan untuk melakukan pengukuran relatif pada lapangan kecil hingga $1 \times 1 \mathrm{~cm}^{2}$ pesawat pemercepat linier medik.

\section{UCAPAN TERIMAKASIH}

Penulis mengucapkan terima kasih yang sebesar-besarnya kepada staf/ fisika medis Rumah Sakit Mayapada, PT Besindo dan teman-teman program magister fisika medis UI atas waktu dan usahanya sehingga penelitian ini dapat terlaksana.

\section{DAFTAR PUSTAKA}

1. Oemiati R, Rahajeng E, Kristanto AY. Di Indonesia penyakit. Bul Penelit Kesehat. 2011;39(4):190-204.

2. Hiswara E. Status terkini dan perspektif masa depan radioterapi di indonesia. In: Prosiding Pertemuan dan Presentasi IImiah Penelitian Dasar IImu Pengetahuan dan Teknologi Nuklir. 2017. p. 47-52.

3. Diah FI, Anggraita P. Tinjauan teknologi akselerator linear (linac) elekta precise di rsup dr. sardjito. 2010;166-75.

4. Firmansyah AF, Wurdiyanto G, Rajagukguk N, Sunaryati SI. Perkembangan Teknologi Pada Pesawat Teleterapi di Indonesia dan Apek Keselamatannya. In: Seminar Keselamatan Nuklir. YOgyakarta; 2017. p. 257-62.

5. Borzov E, Nevelsky A, Bar-Deroma R, Orion I. Dosimetric characterization of Elekta stereotactic cones. J Appl Clin Med Phys. 2018;19(1):194-203.

6. Charles PH. Very Small Field Dosimety. Queensland University of Technology; 2014.

7. Das IJ, Morales J, Francescon P. Small field dosimetry: What have we learnt? AIP Conf Proc. 2016;1747.

8. Andreo P. The physics of small megavoltage photon beam dosimetry q. Radiother Oncol. 2017;126(2):2052013.

9. Papanikolaou N, Stathakis S. Commissioning an Elekta Versa HD linear accelerator. J Appl Clin Med Phys. 2016;17(1):179-91.

10. Agostinelli S, Garelli S, Piergentili M, Foppiano F. Response to high energy photons of PTW31014 PinPoint ion chamber with a central aluminum electrode Response to high energy photons of PTW31014 PinPoint ion 
chamber with a central aluminum

electrode. Med Phys.

2008;35(2008):3293-301.

11. Reggiori G, Mancosu P, Suchowerska N, Lobefalo F, Stravato A, Tomatis S, et al. Characterization of a new unshielded diode for small field dosimetry under flattening filter free beams. Phys Medica. 2016;32(2):408-13.

12. Nasir MKR, Amjad N, Razzaq A, Siddique T. Measurement and Analysis of PDDs Profile and Output Factors for Small Field Sizes by cc13 and Micro-Chamber cc01. Int J Med Physics, Clin Eng Radiat Oncol. 2017;06(01):36-56.

13. Sruti $R N$, Islam $M M$, Rana $M M$, Bhuiyan $\mathrm{MMH}$, Khan KA. Measurement of Percentage Depth Dose of a Linear Accelerator for $6 \mathrm{MV}$ and $10 \mathrm{MV}$ Photon Energies. 2015;24(1):29-32.

14. Ceska D. Reference Detector for Small Fields - The T-Ref Chamber. Med Phys Int J. 2016;4(1):47-52.

15. Das IJ, Francescon P. Comments on the TRS -483 protocol on small field dosimetry. In: Medical Physics. 2018. p. 5666-8. 